\title{
Editorial
}

\section{New Advances in Marine Engineering Geology}

\author{
Xiaolei Liu ${ }^{1}\left(\mathbb{D}\right.$, Qing Yang $^{2}$, Yin Wang ${ }^{2}\left(\mathbb{D}\right.$, Dong-Sheng Jeng ${ }^{3, *(\mathbb{D}}$ and Hendrik Sturm ${ }^{4}(\mathbb{C}$ \\ 1 Shandong Provincial Key Laboratory of Marine Environment and Geological Engineering, \\ Ocean University of China, Qingdao 266100, China; xiaolei@ouc.edu.cn \\ 2 State Key Laboratory of Coastal and Offshore Engineering, School of Civil Engineering, \\ Dalian University of Technology, Dalian 116024, China; qyang@dlut.edu.cn (Q.Y.); y.wang@dlut.edu.cn (Y.W.) \\ 3 School of Engineering and Built Environment, Gold Coast Campus, Griffith University, \\ Southport, QLD 4222, Australia \\ 4 Norwegian Geotechnical Institute (NGI), P.O. Box 3930 Ullevaal Stadion, N-0806 Oslo, Norway; \\ hendrik.sturm@ngi.no \\ * Correspondence: d.jeng@griffith.edu.au
}

check for updates

Citation: Liu, X.; Yang, Q.; Wang, Y.; Jeng, D.-S.; Sturm, H. New Advances in Marine Engineering Geology. J. Mar. Sci. Eng. 2021, 9, 66. https://doi.org/10.3390/jmse 9010066

Received: 2 December 2020 Accepted: 7 January 2021 Published: 11 January 2021

Publisher's Note: MDPI stays neutral with regard to jurisdictional clai$\mathrm{ms}$ in published maps and institutional affiliations.

Copyright: (C) 2021 by the authors. Licensee MDPI, Basel, Switzerland. This article is an open access article distributed under the terms and conditions of the Creative Commons Attribution (CC BY) license (https:// creativecommons.org/licenses/by/ $4.0 /)$.

\section{Introduction}

The ocean is the cradle of life and is rich in natural resources. With the worldwide boom in exploration and application of ocean resources, a dramatic increase in coastal and offshore engineering construction has been observed in the last few decades. The rapid development of human economic activities and changing global climate has had significant impacts on the marine environment, resulting in increased impact from natural disasters. Under this circumstance, there is an urgent need for platform for scientists and engineers to share their state-of-art research outcomes in the field of Marine Engineering Geology.

In order to provide a platform for marine engineering geological researchers and enhance their cohesion, the Commission No. 34-Marine Engineering Geology (C34) was established under the support of the International Association for Engineering Geology and the Environment (IAEG) in Banff, Canada in 2012. In 2016, the First International Symposium on Marine Engineering Geology (ISMEG 2016) was successfully held in Ocean University of China, Qingdao, China.

During the 18-20 October 2019, the 2nd International Symposium on Marine Engineering Geology (ISMEG 2019) was held in Dalian, China. The second international symposium was sponsored by IAEG-C34, hosted by State Key Laboratory of Coastal and Offshore Engineering (Dalian University of Technology), and co-hosted by the Department of Earth Science, National Natural Science Foundation of China and Shandong Provincial Key Laboratory of Marine Environment and Geological Engineering (Ocean University of China) and several other organizations. Nearly 300 representatives from over 70 international research institutions, universities, and businesses attended the symposium, discussed recent advances, shared their knowledge, and identified future research directions in the field of marine engineering geology. The theme of this symposium is "Exploration of Marine Resources and Marine Engineering Geology", covering topics including engineering properties of marine soils, marine geological hazards and preventions, in situ exploration, monitoring, and physical modeling, hydrodynamics and environmental interaction, exploration of gas hydrate, offshore foundations, and pipe-soil-fluid interaction.

The objective of this Special Issue is to collect high-quality papers from ISMEG 2019 participants and provide a timely overview of recent advances and case studies in this field. The issue collected 14 papers that cover different aspects of marine engineering geology and geotechnics using different approaches. Some of them used numerical simulations [1-5], some conducted laboratory experiments [6-10], and others acquired and analyzed field or laboratory tests to establish a theoretical modeling framework for predicting marine sediment properties and the potential hazards [11-14]. Moreover, with a timely and well-organized publication, it is believed that the state-of-the-art data, analyses, and methodologies presented 
in this Special Issue could be of great interest to all readers of Journal of Marine Science and Engineering.

The core aspects of each paper in the special issue are synthesized in the following section.

\section{Papers Details}

Chen et al. [1] present the numerical solution of an improved double-layer foundation consolidation theory, aiming at understanding the characteristics of the marine soft soil double-layer foundation structure with complex drainage conditions. They introduced continuous drainage boundary conditions into the traditional consolidation theory by applying the Laplace's transform and Stehfest algorithm in the derivation process of the model equations. This improved model was validated and analyzed by the degenerated model of the perfectly permeable and the semi-permeable boundary conditions. Moreover, they applied the model to a marine soft soil foundation project in Guangxi, China for the consolidation analysis. The validation of the results against field data shows good performance of the model in the analysis of consolidation and settlement of marine soft soil foundations with complex drainage conditions.

Yu et al. [2] investigate the effect of an existing footprint on the stability of jack-up platform reinstallation. In this study, a large deformation finite element analyses with the coupled Eulerian-Lagrangian (CEL) method was carried out. Attention is focused on the effects of footprint geometry, reinstallation eccentricity, and the roughness between spudcan and soil on the profiles of vertical forces, horizontal forces, and bending moments. They also underline the role of the soil profiles, soil properties, geometry of footprints and spudcans, leg details, use of spigots (or not), etc., in site-specific analyses.

Li et al. [3] investigate the accumulation of pore water pressure in a soft clay seabed around a suction anchor under cyclic loading conditions. They propose a three-dimensional damage-dependent bounding surface model, in which a damage parameter and initial anisotropic tensors are introduced to represent the remolding of the soil structure and initial anisotropy, respectively. The proposed model is validated against available triaxial test data and provides a better description of the cyclic behaviors of soft clay. Li et al. [3] also propose a new structure that can reduce the accumulation of excess pore water pressure based on the numerical simulations.

Han et al. [4] investigate the flow field dynamics and corresponding response of a porous seabed around an immersed tunnel under wave loading combined current with various velocities. They developed a $2 \mathrm{D}$ numerical model, which is composed of two sub-models: The flow model with OpenFOAM and the seabed model with a Meshfree method, to simulate the fluid-structure-seabed interaction. The integrated model is well validated by comparison with the analytical solution and experimental data. The numerical results confirmed that the existence of the immersed tunnel affected surrounding seabed dynamic behaviors, and thus weakened the displacement and dynamic pore pressure change nearby. The parametric studies also reveal the significant impact of wave characteristics, soil properties, and current velocities on the liquefaction behavior in the vicinity of an immersed tunnel.

Li et al. [5] present a numerical investigation on the influence of flap geometric parameters on the aerodynamic characteristics of two-element wingsail. They propose a two-element wingsail model by using the steady and unsteady RANS approach with the SST k- $\omega$ turbulence model. Existing experimental data are used to ensure the accuracy of the numerical simulation. Moreover, it provides a quantitative evaluation regarding the aerodynamic characteristics of the wingsail with different structural parameters including camber, the rotating axis position of the flap, angle of attack, and flap thickness.

Cui et al. [6] illustrate a framework to analyze the hydrodynamic dispersion characteristics of coral sands in marine environments. In particular, they explore how the dispersion characteristics of solute in calcareous sands are influenced by the particle size, degree of compactness, and gradation of porous media. They used coral sands collected from a reef in the South China Sea and conducted a series of laboratory tests and theoretical analyses. 
Results reveal a direct correlation between the dispersion coefficients of coral sands and the above-mentioned factors. Moreover, they find that the dispersion mechanisms in coral sands could be determined by the flow velocity of the pore fluid.

Wang et al. [7] explore the instability behavior of the fine-grained seabed under wave action. In particular, they carried out a series of in-lab flume experiments using the sediment collected in the subaqueous Yellow River delta. Results reveal an oscillation failure type characterized by an arc-shaped sliding surface. Moreover, they find that the presence of gas plays a key role in promoting the occurrence of submarine slope failures.

$\mathrm{Lu}$ et al. [8] investigate the remobilization of heavy metal $\mathrm{Cu}$ under wave action, especially during sediment liquefaction. They conducted a series of controlled wave flume experiments using the sandy silts collected from the Yellow River Delta. The experimental results indicate that sediment liquefaction significantly promotes the release of $\mathrm{Cu}$ from internal sediment to the overlying water. Moreover, they analyzed the pattern and mechanism of migration and diffusion of dissolved $\mathrm{Cu}$ in different stages. The study may provide a reference for understanding changes of the marine ecological environment in the subaqueous Yellow River Delta.

$\mathrm{Wu}$ et al. [9] investigate the dynamic response characteristics of the pile-soil-structure system in coral sand under earthquake. They conducted a series of shaking table tests of three-story structures with a nine-pile foundation in coral sand and Fujian sand, respectively. The influence of shaking intensity on the dynamic response of the system has been taken into consideration by the authors. In this way, they are able to compare the similarities and differences between dynamic characteristics of coral and Fujian sand based on the results of pore water pressure, acceleration, displacement, and dynamic bending moment. This work may provide some references for the seismic design of coral reef projects.

Liu et al. [10] examine the possibility of using the pressure sensing technique for observing seabed deformation caused by submarine sand wave migration. They developed two pressure sensing tools, a fixed-depth total pressure recorder and a surface synchronous bottom pressure recorder, to make observations in laboratory flume experiments. The proposed pressure sensor techniques have been proven by the results to effectively reflect elevation caused by submarine sand wave migration with an accuracy more than $90 \%$. Moreover, authors discuss the reliability and limitations of using the two methods in practical observations. This work suggests an important way for guiding the monitoring and early detection of bedforms and sediment mobility and better understanding the mechanisms of submarine sand wave migration.

Guo et al. [11] present an exploration into identifying the interactions between ocean waves and the continental margin in the generation of double-frequency (DF, $0.1-0.5 \mathrm{~Hz}$ ) microseisms. They collected a total of 10 days of ambient noise data at 33 stations across the East Coast of USA. Both the observations and correlation analyses led to a hypothesis on the frequency dependent interactions of ocean waves with the continental margin and the origination of DF microseisms. This work suggests a potential contribution of the frequency-dependent interactions between the ocean waves and the continental margin determined in analyzing the wave-induced mass wasting on the continental margin.

$\mathrm{Wu}$ et al. [12] present an experimental investigation on the small-strain stiffness of marine silty sand. They conducted a series of bender element tests on marine silty sand with fines content ranging from $0 \%$ to $30 \%$ under isotropic consolidation. Moreover, they discuss the influence of parameters in the established framework based on clean sand. In particular, a binary packing state concept was implemented to modify the Hardin model for evaluation of the small-strain stiffness of marine silty sand. The proposed model has been calibrated by the independent test data for different silty sand published in the literature.

Jun and Kwon [13] propose the representative constitutive relationship equations of marine soft soil in Korea. They collected samples at 23 dredged reclaimed construction sites in three regions in Korea. In particular, the consolidation simulations were carried out at a high void ratio using the centrifugal experiment to realize high water content and in-field stress conditions. Then the void ratio-effective stress and void ratio-permeability 
coefficient were estimated using the back analysis. The constitutive relationship for Korean soft soil was determined to be a reasonable power function equation. They also underline the importance of a design chart based on the constitutive relationship equations.

Huang and Han [14] summarize seismic liquefaction field investigations in marine engineering to provide a systematic understanding of the historical cases published over recent decades. Particularly, they identified the effects of seawater and the gas component in the marine seabed layers, leading to a larger liquefied area than when liquefaction occurs on land. Moreover, they review mitigation strategies of novel marine foundation structures considering their resistance of liquefaction.

Author Contributions: Conceptualization, X.L. and D.-S.J.; Writing-original draft, X.L.; Writingreview \& editing, D.-S.J., Q.Y., Y.W. and H.S. All authors have read and agreed to the published version of the manuscript.

Funding: This research received no external funding.

Data Availability Statement: The data presented in this study are available on request from the corresponding author.

Acknowledgments: We want to express our sincere thanks to all the authors and the reviewers.

Conflicts of Interest: The authors declare no conflict of interest.

\section{References}

1. Chen, D.; Luo, J.; Liu, X.; Mi, D.; Xu, L. Improved Double-Layer Soil Consolidation Theory and Its Application in Marine Soft Soil Engineering. J. Mar. Sci. Eng. 2019, 7, 156. [CrossRef]

2. Yu, L.; Zhang, H.; Li, J.; Wang, X. Finite Element Analysis and Parametric Study of Spudcan Footing Geometries Penetrating Clay Near Existing Footprints. J. Mar. Sci. Eng. 2019, 7, 175. [CrossRef]

3. Li, H.; Chen, X.; Hu, C.; Wang, S.; Liu, J. Accumulation of Pore Pressure in a Soft Clay Seabed around a Suction Anchor Subjected to Cyclic Loads. J. Mar. Sci. Eng. 2019, 7, 308. [CrossRef]

4. Han, S.; Jeng, D.-S.; Tsai, C.-C. Response of a Porous Seabed around an Immersed Tunnel under Wave Loading: Meshfree Model. J. Mar. Sci. Eng. 2019, 7, 369. [CrossRef]

5. Li, C.; Wang, H.; Sun, P. Numerical Investigation of a Two-Element Wingsail for Ship Auxiliary Propulsion. J. Mar. Sci. Eng. 2020, 8, 333. [CrossRef]

6. Cui, X.; Zhu, C.; Hu, M.; Wang, X.; Liu, H. The Hydrodynamic Dispersion Characteristics of Coral Sands. J. Mar. Sci. Eng. 2019, 7, 291. [CrossRef]

7. Wang, X.; Zhu, C.; Liu, H. Wave-Induced Seafloor Instability in the Yellow River Delta: Flume Experiments. J. Mar. Sci. Eng. 2019, 7, 356. [CrossRef]

8. Lu, F.; Zhang, H.; Jia, Y.; Liu, W.; Wang, H. Migration and Diffusion of Heavy Metal Cu from the Interior of Sediment during Wave-Induced Sediment Liquefaction Process. J. Mar. Sci. Eng. 2019, 7, 449. [CrossRef]

9. Wu, Q.; Ding, X.; Zhang, Y.; Chen, Z. Comparative Study on Seismic Response of Pile Group Foundation in Coral Sand and Fujian Sand. J. Mar. Sci. Eng. 2020, 8, 189. [CrossRef]

10. Liu, X.; Zheng, X.; Tian, Z.; Zhang, H.; Chen, T. Pressure Sensing Technique for Observing Seabed Deformation Caused by Submarine Sand Wave Migration. J. Mar. Sci. Eng. 2020, 8, 315. [CrossRef]

11. Guo, Z.; Huang, Y.; Aydin, A.; Xue, M. Identifying the Frequency Dependent Interactions between Ocean Waves and the Continental Margin on Seismic Noise Recordings. J. Mar. Sci. Eng. 2020, 8, 134. [CrossRef]

12. Wu, Q.; Lu, Q.; Guo, Q.; Zhao, K.; Chen, P.; Chen, G. Experimental Investigation on Small-Strain Stiffness of Marine Silty Sand. J. Mar. Sci. Eng. 2020, 8, 360. [CrossRef]

13. Jun, S.H.; Kwon, H.J. Constitutive Relationship Proposition of Marine Soft Soil in Korea Using Finite Strain Consolidation Theory. J. Mar. Sci. Eng. 2020, 8, 429. [CrossRef]

14. Huang, Y.; Han, X. Features of Earthquake-Induced Seabed Liquefaction and Mitigation Strategies of Novel Marine Structures. J. Mar. Sci. Eng. 2020, 8, 310. [CrossRef] 